\title{
Variability and sequential effects in magnitude production and estimation of auditory intensity
}

\author{
DAVID M. GREEN, R. DUNCAN LUCE, and JOSEPH E. DUNCAN \\ Laboratory of Psychophysics, Harvard University, Cambridge, Massachusetts 02138
}

\begin{abstract}
Magnitude production and estimation data from the same subjects are analyzed in three ways. The coefficient of variation of the ratio of successive responses (numbers in estimation, SPL in production) are compared; both exhibit, as a function of stimulus difference, the V-shaped pattern previously found in estimation data. A multiple regression of responses on the stimulus and on these events of the previous trial exhibit similar patterns, although the effects of the previous trial in production are somewhat less. The correlation between successive responses, averaged over constant stimulus differences, are very large for small differences and about zero for large ones. These somewhat surprisng results for production are examined from the point of view of an intensity attention band hypothesis.
\end{abstract}

We have previously investigated the variability of individual judgments of loudness in a magnitudeestimation task (Green \& Luce, 1974). Later, we examined the sequential effects present in such individual judgments and how those effects could be characterized and analyzed (Jesteadt, Luce, \& Green, 1977). This paper reports data on individual adjustments of loudness in a magnitude-production experiment, together with magnitude-estimation data from the same subjects. Both variability and the sequential effects present in the production and the estimation task are compared.

The paper is organized as follows: The procedures used to collect the data in the two experiments are first described. Then the results from the two experiments are compared as to mean responses, the variability of the individual judgments, and the sequential effects.

\section{PROCEDURE}

Throughout, the signals were $1,000-\mathrm{Hz}$ tones of $500-\mathrm{msec}$ duration. They were presented binaurally, in quiet, through SW-2 Superex headphones, and subjects listened in a single-wall sound room (IAC-402A). The presentation of the signals was controlled from a digital computer (PDP-15), and the observers communicated with the computer through a special response box containing a keyboard with 16 keys (digits $0-9$ plus 6 control functions) and a small LED display (5 possible characters).

The five subjects practiced for about 2 days ( 600 trials) before the production data were recorded and about 1 day (600 trials) before the magnitude-estimation data were collected. They

This work was supported in part by National Science Foundation grants to Harvard University. We wish to thank Drs. D. V. Cross, L. E. Marks, and R. Teghtsoonian for their thoughtful comments on an earlier draft. Especially helpful were Cross's remarks which uncovered a serious error in the original version. participated $2 \mathrm{~h}$ a day for about 6 to 8 days in the course of the experiments. They were paid an hourly rate for their participation.

\section{Production}

Each trial of the magnitude production task began with a number presented on the subject's LED display. As it appeared, tone bursts began-500 msec on, $500 \mathrm{msec}$ off. The starting intensity of the tone was chosen at random in the range 40-90 dB with 1-dB steps. The subject could adjust the intensity by pushing one of four buttons. Two of the buttons provided gross adjustment of the tones-in 4-, 5-, or 6-dB steps-one button increasing and the other decreasing intensity. The step size was randomized so that the number of intensity changes did not exactly correspond to the change in level of the tone, e.g., the subject could not set the stimulus exactly $24 \mathrm{~dB}$ above threshold by first decreasing it to threshold and then increasing it $6 \mathrm{~dB}$ four times. The other two buttons produced 1-dB changes in the stimulus level once the gross adjustment was complete. The equipment permitted the subject to adjust the tone from absolute threshold to $95 \mathrm{~dB}$ SPL. Once the subject achieved the desired intensity level, the tone repeated until the subject pressed a "clear" button which initiated the next trial. The subject was instructed to adjust the final loudness of successive trials to equal the ratio of successive numbers.

The numbers used in the magnitude production task were: $2,3,4,5,6,8,10,15,20,25,30,40,50,60,80,100,150,200,250$, and 300 . They were chosen (1) because they were numbers commonly used by other subjects in previous estimation experiments and (2) because the ratios of many of the pairs are the same, $2 / 4,100 / 200$, etc. Each was equally likely to be selected on a trial. Typically, 360 adjustments were completed in a 2 -h session. Blocks of 120 adjustments were separated by rest periods.

\section{Estimation}

The magnitude-estimation experiment was run after the production experiment was completed. Each presentation was a single 500 -msec tone burst, whose intensity was chosen at random from 40 to $80 \mathrm{~dB}$ SPL in 2-dB steps. The tones did not repeat as in the production experiment. The subject was to assign a number to the tone so that the ratio of successive numbers reflected the ratio of successive loudnesses.

After each presentation, the subject responded by depressing the appropriate numbers-integers only, in the range 1-99,999. The number thus entered then appeared on the LED display. Any 
mistake could be cleared and another number entered. Finally, when satisfied with his or her response, the subject pushed a different button which caused the response to be recorded in the computer and initiated the next trial. Typically, about 600 adjustments were completed during a 2 -h session. Blocks of 120 trials were separated by rest periods.

\section{RESULTS}

\section{Mean Response}

Figure 1 shows the mean responses for both the production and the estimation tasks along with the variability $(+1 \sigma)$ of each response for each of the five subjects. For the production data, means and standard deviations are simply computed from the sound pressure level in decibels of the adjustments made to a particular number. For the estimation data, means and standard deviations are computed from the logarithm of the numerical response given to a particular sound pressure level. The logarithm of the responses was used so that the variability would be nearly the same at all intensities. The anti$\log$ of the computed mean is the geometric mean of the original responses.

The average data from each experiment can be described as roughly a power function, $R=\mathrm{kI}^{r}$, where $\mathbf{R}$ is the number assigned to intensity $\mathbf{I}$ (measured in watts $/ \mathrm{cm}^{2}$ ), $\mathrm{k}$ is a constant, and $\gamma$ is the power-law exponent (slope in Figure 1). There are some noticeable discrepancies from this simple description for some subjects and conditions; especially noticeable is subject F.S. in the magnitude production experiment. Least square (log-log coordinates) estimates of the parameters $\gamma$ and $\mathrm{k}$ are shown in Table 1.

As the equations of the table indicate, the independent and dependent variables are interchanged in the two tasks. Thus we also display the reciprocal of the magnitude production slope so that it can be compared directly with the slope, or power law exponent, of the magnitude-estimation experiment. For all subjects, the comparable slope, $\gamma^{\prime}$, estimated from the production data is appreciably larger thąn the slope, $\gamma$, estimated from the estimation data.

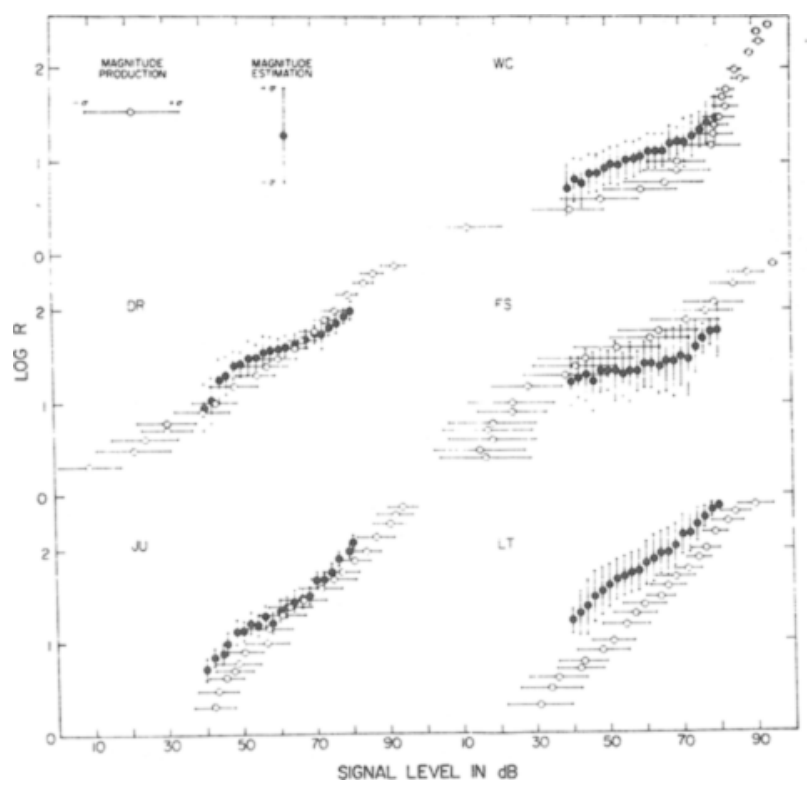

Figure 1. Magnitude estimations and productions in log-log coordinates. The ordinate is the logarithm of numbers and the abscissa is SPL in dB. The former is the dependent variable for estimation and the independent variable for production. The bars show estimated one-standard-deviation bands.

This is the well-known regression effect (Stevens \& Greenbaum, 1966; Stevens, 1975).

\section{Variability of Responses}

Careful inspection of Figure 1 reveals that the variability of the magnitude productions (shown by the $\pm \sigma$ bands) decreases with increasing signal level. We have studied this phenomenon in a number of different ways, but perhaps the simplest is to ask a subject repeatedly to adjust a tone to one or the other of two prescribed levels, one loud, one soft. The standard deviation of such adjustments is smaller for the louder tone than it is for the softer one. All adjustments to one level can be made before beginning those at the next level without altering the result. Figure 2 shows the mean and variability

Table 1

\begin{tabular}{|c|c|c|c|c|c|}
\hline \multirow[b]{2}{*}{ Subject } & \multicolumn{2}{|c|}{$\begin{array}{c}\text { Magnitude Production } \\
\log I=\left(1 / \gamma^{\prime}\right) \log R+\log c\end{array}$} & \multirow[b]{2}{*}{$\gamma^{\prime}$} & \multicolumn{2}{|c|}{$\begin{array}{l}\text { Magnitude Estimation } \\
\log \mathrm{R}=\gamma \log \mathrm{I}+\log \mathrm{k}\end{array}$} \\
\hline & $\begin{array}{l}\text { Slope } \\
1 / \gamma^{\prime}\end{array}$ & $\begin{array}{c}\text { Intercept } \\
\log \mathrm{c}\end{array}$ & & $\begin{array}{c}\text { Slope } \\
\gamma \\
\end{array}$ & $\begin{array}{c}\text { Intercept } \\
\log \mathrm{k}\end{array}$ \\
\hline $\begin{array}{l}\text { W.C. } \\
\text { D.R. } \\
\text { F.S. } \\
\text { J.U. } \\
\text { L.T. }\end{array}$ & $\begin{array}{l}2.66 \\
3.57 \\
4.04 \\
2.59 \\
2.67\end{array}$ & $\begin{array}{r}3.64 \\
0.46 \\
-0.95 \\
2.97 \\
2.27\end{array}$ & $\begin{array}{l}0.38 \\
0.28 \\
0.25 \\
0.39 \\
0.37\end{array}$ & $\begin{array}{l}0.17 \\
0.19 \\
0.12 \\
0.28 \\
0.29\end{array}$ & $\begin{array}{r}0.13 \\
0.43 \\
0.81 \\
-0.24 \\
0.13\end{array}$ \\
\hline Average & & & 0.33 & 0.20 & \\
\hline
\end{tabular}




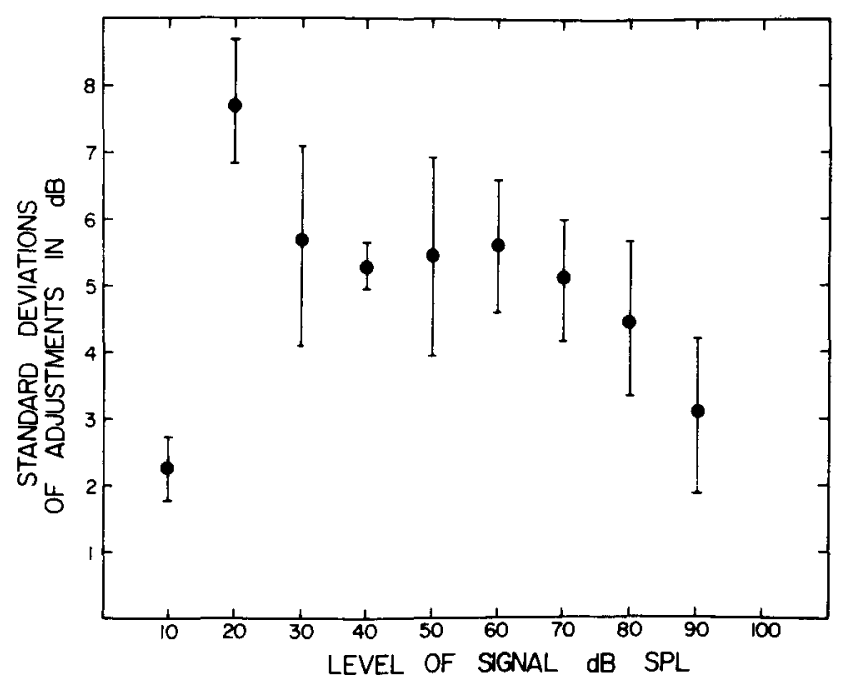

Figure 2. Standard deviation of magnitude productions as a function of approximate level of the signal. Various different experimental procedures have been combined to produce this figure, and the number of subjects and adjustments vary.

across subjects of the standard deviations of adjustments made at a variety of signal levels and under a variety of different experimental situations. The adjustments at $10 \mathrm{~dB}$ SPL are near absolute threshold and show little variability. Except for this point, the standard deviation of the adjustment diminishes by about a factor of 2-3 over the audible range. Because not all subjects were run at the same times, the number of subjects entering each mean varies, but a typical value is 8 . One subject had standard deviations about twice the means shown in the figure and so was excluded in the analysis. Even with this extreme variability, the same decrease of standard deviation with signal level occurred.

A direct comparison of the variability of magnitude production and magnitude estimation data is difficult, because of the nonlinear relation between signal intensity, I, and the subject's response, $R$. Taking the logarithm of each variable produces an approximately linear relation, but the slope is not unity. Thus, even if the variability was due to a common source, we would expect the estimated standard deviations to differ by the proportionality constant relating the two measures. For this reason, we use the following scheme to facilitate direct comparison of the variability. We transformed each response from the magnitude-production task into a numerical response in two ways: by using the linear regression equation estimated from the same subject's magnitude-estimation data and by the inverse of the regression estimated from his production data. Thus, in the first procedure a given sound pressure level in the production task is converted to the expected response of the same subject in a magnitude-estimation experiment. In the second procedure, the conversion is to the number that, on the average, produced this sound pressure level in the production task. It is far from clear which is the more appropriate to use, so we present both and compare them directly to the data from the magnitudeestimation experiment.

Figure 3 shows variability of responses, constructed as above, as a function of the difference in stimulus in decibels in successive trials. The cocrdinates of Figure 3 deserve discussion. The ordinate for the first two panels of the figure is the coefficient of variation $(\sigma / \mathrm{m})$ computed from the ratio of responses $\left(R_{n} / R_{n-1}\right)$ given on successive trials. For the production data, this is the ratio of transformed responses as just discussed. The ratio of responses was used in the calculation, not the logarithm of the ratio, so that it could be compared with some previous data. The ordinate for the third panel is the coefficient of variation of the production

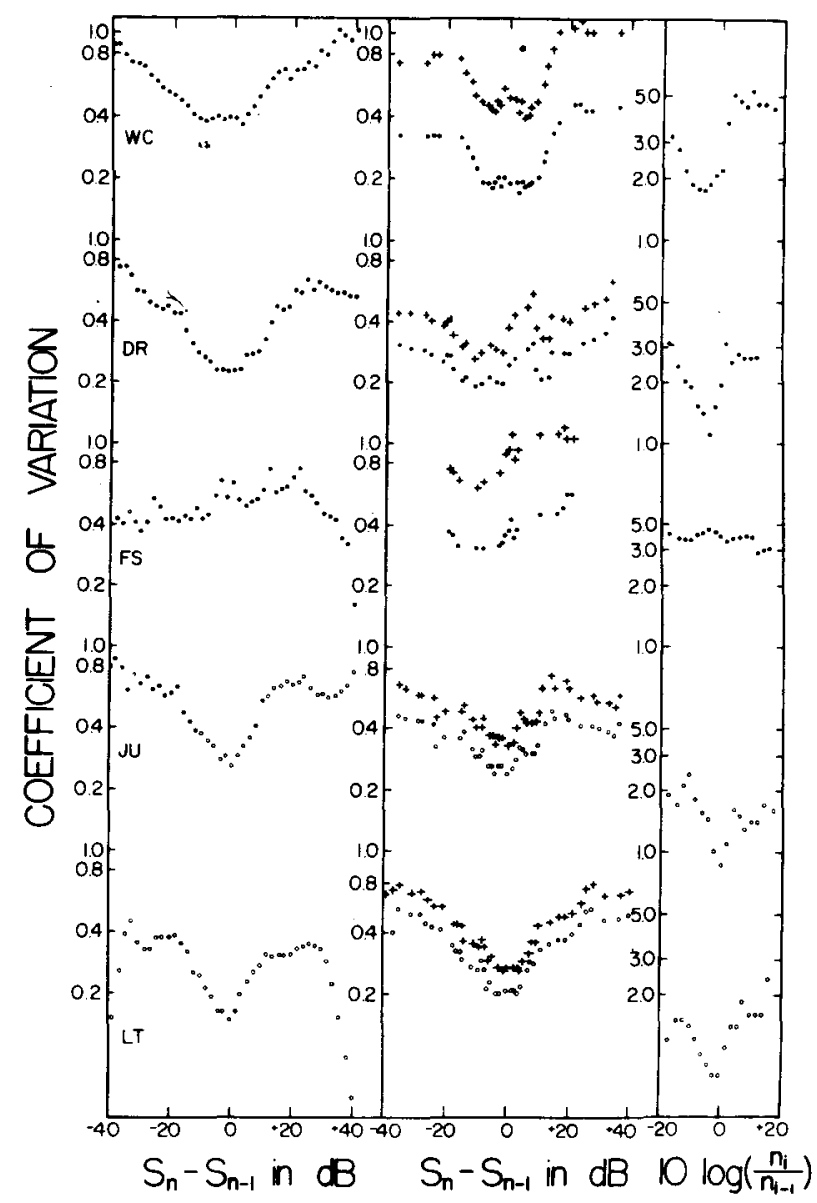

Figure 3. The coefficient of variation of $R_{n} / R_{n-1}$ from magnitude estimation (left panel) and from the transformed magnitude productions (center panel), and the coefficient of variation of $I_{n} / I_{n-1}$ from magnitude production (right panel). See the text for an explanation of the transformations. 
responses computed from the adjusted value in decibels. The abscissa for the first panel is simply the decibel change in the stimulus on successive trials $\left(S_{n}-S_{n-1}\right)$. The abscissa for the second panel is simply the difference in decibels between successive adjustments in the production task.

The data of the first two panels have been smoothed by a running average of neighboring points along the abscissa, using the following weights: $1 / 8$, $1 / 4,1 / 2,1,1 / 2,1 / 4,1 / 8$. The abscissa for the third panel is the logarithm of the ratio of numbers presented as stimuli on successive trials [ $\left.\log R_{n} / R_{n-1}\right]$ in the production task. Because many of the ratios were nearly the same, especially near a ratio of unity, the data have been averaged over $2 / 10 \log$ steps, and only points exceeding that range are plotted separately.

It is difficult to compare the variability in magnitude estimation and magnitude production, first, because it is unclear how the comparison should be made, and second, no matter how the comparison is made the subjects show different trends. For example, subject W.C. in Figure 3 shows about the same pattern of variability when the magnitude estimation data is compared with the transformed production data using the inverse of the production function, and less variability when the data is transformed by the magnitude estimation function, whereas subject L.T. showed more variability in the production task for both forms of the transform.

The final panel, on the extreme right in Figure.3, displays for the production data the coefficient of variability of the signal settings in decibels as a function of the difference in numbers on successive trials.

An earlier paper, Green and Luce (1974), showed that this coefficient of variability depended heavily on the difference in the stimulus on two successive trials. This pattern, when plotted as in Figure 3, has been called a V-shaped pattern (Baird, 1970). Although, in the previous paper, we combined the data for comparable positive and negative changes, the pattern observed here and there is essentially identical. A small change in successive stimuli produces a coefficient of variation that is smaller by a factor of from three to five times when the stimulus change is larger. The single exception to this generalization is subject F.S., who is our first subject who does not display the $V$-shaped pattern.

It came as a surprise that the same pattern occurs in the magnitude production data. The reasons for our surprise are the fact that the production responses are more widely separated in time than the estimation judgments, and because the first sound heard by the subject in the production task is chosen at random throughout a large range of intensities. Thus the actual change in decibels from his last re- sponse to the first signal that he hears in the next trial of the production task is in general quite unrelated to the final value selected.

The result is also surprising from a theoretical view, since it was suggested, on the basis of previous observations in the magnitude estimation task, that the $\mathrm{V}$-shaped pattern might reflect an attention band. In particular, we assumed that there was a band of intensities, about 15-20 dB wide and of variable location, such that when a signal fell within the band it would receive an internal representation based on a sample size about 10 times as large as when it fell outside the band. If such a band tends to be located where the last signal was, then whenever successive signals are close the second will receive the large sample size, therefore be less variable, and so the responses will exhibit the V-shaped pattern. Formally, the same argument leads to the same conclusion in the production experiment, but we did not really anticipate that it would apply for the following reason. At the onset of a new production trial, the signal is reset at a random intensity and then the subject adjusts it through a number of intervening values until he feels it is suitable for the numerical stimulus given him on that trial. Thus, for the band argument to work here, one must assume that it remains fixed in the vicinity of the setting on the last trial throughout all the intervening changes. Since we do not understand at all what controls its location, we cannot really say whether or not this can happen, but intuitively it is surprising.

\section{Sequential Effects: Multiple Regression Equation}

Previous work (Cross, 1973; Helson, 1948; Holland \& Lockhead, 1968; Ward, 1972, 1973; Ward \& Lockhead, 1970, 1971) on magnitude estimation and category rating has shown that the present response, although mainly determined by the present signal, is somewhat affected by the previous signal and the previous response. (We have also studied the influence of responses and signals more than one trial removed; in our opinion, their impact is very slight.) Table 2 presents the regression parameters for a simple multiple regression for the current response on the present stimulus, the immediately preceding stimulus, and the immediately preceding response, where the stimuli are log numbers, in the case of production, and sound pressure level in decibels, in the case of estimation, and the responses are just the reverse. In order to facilitate comparison, we have again presented the production data transformed into numerical responses having the same range as the magnitude estimation numbers. One should recall that the first parameter, gamma, of the transformed data must, except for roundoff errors, come out to be the same as the estimation data be- 
Table 2

Parameters of Regression Equation

$\mathbf{Y}_{n}=\gamma \mathbf{X}_{n}+\alpha \mathbf{X}_{n-1}+\beta \mathbf{Y}_{n-1}+\delta$

\begin{tabular}{|c|c|c|c|c|c|c|c|c|}
\hline Subject & Procedure & $\gamma$ & $\alpha$ & $\beta$ & $\delta$ & $\mathbf{R}$ & $\mathbf{R}^{2}$ & $N$ \\
\hline W.C. & $\begin{array}{l}\text { Prod* } \\
\text { Trans** } \\
\text { Est** }\end{array}$ & $\begin{array}{r}2.573 \\
.154 \\
.173\end{array}$ & $\begin{array}{r}-.034 \\
-.024 \\
-.042\end{array}$ & $\begin{array}{l}.018 \\
.167 \\
.411\end{array}$ & $\begin{array}{r}3.686 \\
.181 \\
-.150\end{array}$ & $\begin{array}{l}.829 \\
.948 \\
.771\end{array}$ & $\begin{array}{l}.687 \\
.899 \\
.595\end{array}$ & $\begin{array}{l}2545 \\
2485\end{array}$ \\
\hline D.R. & $\begin{array}{l}\text { Prod } \\
\text { Trans } \\
\text { Est }\end{array}$ & $\begin{array}{r}3.545 \\
.192 \\
.210\end{array}$ & $\begin{array}{r}-1.127 \\
-\quad .082 \\
-.066\end{array}$ & $\begin{array}{l}.312 \\
.416 \\
.426\end{array}$ & $\begin{array}{l}.377 \\
.268 \\
.036\end{array}$ & $\begin{array}{l}.963 \\
.968 \\
.872\end{array}$ & $\begin{array}{l}.927 \\
.937 \\
.761\end{array}$ & $\begin{array}{l}2569 \\
2511\end{array}$ \\
\hline F.S. & $\begin{array}{l}\text { Prod } \\
\text { Trans } \\
\text { Est }\end{array}$ & $\begin{array}{r}3.986 \\
.106 \\
.120\end{array}$ & $\begin{array}{r}-.785 \\
-.021 \\
-.051\end{array}$ & $\begin{array}{l}.146 \\
.155 \\
.636\end{array}$ & $\begin{array}{r}-.411 \\
.812 \\
.118\end{array}$ & $\begin{array}{l}.924 \\
.925 \\
.774\end{array}$ & $\begin{array}{l}.854 \\
.855 \\
.600\end{array}$ & $\begin{array}{l}2290 \\
1149\end{array}$ \\
\hline J.U. & $\begin{array}{l}\text { Prod } \\
\text { Trans } \\
\text { Est }\end{array}$ & $\begin{array}{r}2.575 \\
.284 \\
.302\end{array}$ & $\begin{array}{r}-1.144 \\
-.136 \\
-.126\end{array}$ & $\begin{array}{l}.395 \\
.437 \\
.615\end{array}$ & $\begin{array}{l}1.990 \\
-.051 \\
-.524\end{array}$ & $\begin{array}{l}.959 \\
.964 \\
.897\end{array}$ & $\begin{array}{l}.919 \\
.930 \\
.804\end{array}$ & $\begin{array}{l}1200 \\
1193\end{array}$ \\
\hline L.T. & $\begin{array}{l}\text { Prod } \\
\text { Trans } \\
\text { Est }\end{array}$ & $\begin{array}{r}2.676 \\
.289 \\
.292\end{array}$ & $\begin{array}{r}-1.305 \\
-.151 \\
-.148\end{array}$ & $\begin{array}{l}.493 \\
.521 \\
.569\end{array}$ & $\begin{array}{r}1.151 \\
.062 \\
-.078\end{array}$ & $\begin{array}{l}.959 \\
.960 \\
.949\end{array}$ & $\begin{array}{l}.919 \\
.921 \\
.900\end{array}$ & $\begin{array}{l}1200 \\
1198\end{array}$ \\
\hline Mean & $\begin{array}{l}\text { Prod } \\
\text { Trans } \\
\text { Est } \\
\text { Jesteadt et al. }\end{array}$ & $\begin{array}{r}3.071 \\
.205 \\
.219 \\
.273\end{array}$ & $\begin{array}{l}-.879 \\
-.083 \\
-.087 \\
-.052\end{array}$ & $\begin{array}{l}.273 \\
.339 \\
.531 \\
.382\end{array}$ & $\begin{array}{r}1.359 \\
.254 \\
-.120 \\
-.307\end{array}$ & $\begin{array}{l}.927 \\
.953 \\
.853 \\
.914\end{array}$ & $\begin{array}{l}.861 \\
.908 \\
.732 \\
.841\end{array}$ & \\
\hline Sigma & $\begin{array}{l}\text { Prod } \\
\text { Trans } \\
\text { Est }\end{array}$ & $\begin{array}{l}.654 \\
.080 \\
.078\end{array}$ & $\begin{array}{l}.509 \\
.061 \\
.047\end{array}$ & $\begin{array}{l}.191 \\
.167 \\
.106\end{array}$ & $\begin{array}{r}1.577 \\
.334 \\
.248\end{array}$ & $\begin{array}{l}.057 \\
.017 \\
.078\end{array}$ & $\begin{array}{l}.102 \\
.033 \\
.133\end{array}$ & \\
\hline
\end{tabular}

*For production, $Y_{n}=S_{n}, X_{n}=R_{n}, X_{n-1}=R_{n-1}, Y_{n-1}=S_{n-1}$.

${ }^{* *}$ For magnitude estimation or the transformed production, $Y_{n}=R_{n}, X_{n}=S_{n}, X_{n-1}=S_{n-1}, Y_{n-1}=R_{n-1}$.

cause each production response was transformed to a magnitude estimate number via the magnitude estimation first-order regression line.

The sequential effects measured in the two procedures appear to be similar. However, there is a tendency, sizable in some subjects, for the coefficient of the response on trial $n-1, Y_{n-1}$, to be somewhat smaller in the transformed production data than in the estimation data. The coefficient of the previous stimulus, $X_{n-1}$, is roughly the same size in both procedures and is smaller than the coefficient of the present stimulus, $X_{n}$. Note that the estimate of $\gamma$ from the multiple regression procedure is nearly the same as that estimated from $X_{n}$ alone (see Table 1). The final rows of the table show the mean parameter estimates, their standard deviations over the five subjects, and the mean parameters estimated from Jesteadt et al. (1977) data. The average parameters for these subjects is within a standard deviation of the mean of the four subjects in the earlier experiment.

Table 3 shows the increment in the multiple correlation due to each additional variable beyond the stimulus on the current trial. The column headed "starting level" is the initial sound, chosen at random, which starts the adjustment procedure. The pattern for the production data is somewhat different from that of the estimation data. In practically all cases, the increment in the multiple correlation produced by adding variables from the previous trial is very small, .003 maximum, in the magnitude production data. This conclusion does not change whether the analysis is done directly on the

Table 3

Increment in Multiple Correlations Produced by Adding Additional Variables

\begin{tabular}{|c|c|c|c|c|c|c|}
\hline Subject & & $\mathbf{X n}$ & $\mathbf{Y}_{\mathbf{n}-1}$ & $x_{n-1}$ & $\begin{array}{c}\text { Starting } \\
\text { Level }\end{array}$ & $\mathbf{N}$ \\
\hline W.C. & $\begin{array}{l}\text { Prod } \\
\text { Trans } \\
\text { Est }\end{array}$ & $\begin{array}{l}.687 \\
.896 \\
.496\end{array}$ & $\begin{array}{l}.000 \\
.001 \\
.083\end{array}$ & $\begin{array}{l}.000 \\
.000 \\
.013\end{array}$ & .000 & $\begin{array}{l}2545 \\
2485\end{array}$ \\
\hline D.R. & $\begin{array}{l}\text { Prod } \\
\text { Trans } \\
\text { Est }\end{array}$ & $\begin{array}{l}.919 \\
.924 \\
.696\end{array}$ & $\begin{array}{l}.000 \\
.000 \\
.043\end{array}$ & $\begin{array}{l}.000 \\
.000 \\
.008\end{array}$ & .000 & $\begin{array}{l}2569 \\
2511\end{array}$ \\
\hline F.S. & $\begin{array}{l}\text { Prod } \\
\text { Trans } \\
\text { Est }\end{array}$ & $\begin{array}{l}.848 \\
.850 \\
.332\end{array}$ & $\begin{array}{l}.000 \\
.000 \\
.230\end{array}$ & $\begin{array}{l}.002 \\
.001 \\
.013\end{array}$ & .001 & $\begin{array}{l}2290 \\
1149\end{array}$ \\
\hline J.U. & $\begin{array}{l}\text { Prod } \\
\text { Trans } \\
\text { Est }\end{array}$ & $\begin{array}{l}.901 \\
.911 \\
.643\end{array}$ & $\begin{array}{l}.000 \\
.000 \\
.122\end{array}$ & $\begin{array}{l}.002 \\
.002 \\
.026\end{array}$ & .002 & $\begin{array}{l}1200 \\
1193\end{array}$ \\
\hline L.T. & $\begin{array}{l}\text { Prod } \\
\text { Trans } \\
\text { Est }\end{array}$ & $\begin{array}{l}.892 \\
.903 \\
.847\end{array}$ & $\begin{array}{l}.003 \\
.003 \\
.019\end{array}$ & $\begin{array}{l}.000 \\
.000 \\
.003\end{array}$ & .001 & $\begin{array}{l}1200 \\
1198\end{array}$ \\
\hline Mean & $\begin{array}{l}\text { Prod } \\
\text { Trans } \\
\text { Est } \\
\text { Jesteadt et al. }\end{array}$ & $\begin{array}{l}.849 \\
.897 \\
.603 \\
.756\end{array}$ & $\begin{array}{l}.001 \\
.001 \\
.099 \\
.061\end{array}$ & $\begin{array}{l}.001 \\
.001 \\
.013 \\
.029\end{array}$ & .001 & \\
\hline SD & $\begin{array}{l}\text { Prod } \\
\text { Trans } \\
\text { Est }\end{array}$ & $\begin{array}{l}.094 \\
.028 \\
.197\end{array}$ & $\begin{array}{l}.001 \\
.001 \\
.082\end{array}$ & $\begin{array}{l}.001 \\
.001 \\
.009\end{array}$ & .001 & \\
\hline
\end{tabular}


production data or on the transformed data. Possibly there is no strong influence of the preceding trial because the subject hears a variety of tones, starting at random intensity, before rendering his final adjustment, or perhaps because the time between trials tends to be longer in the production task. The estimation data obtained from these subjects is very similar to those of Jesteadt et al. (1977), although the firstorder correlation is somewhat smaller.

\section{Sequential Effects: Correlation of Successive Responses}

Jesteadt et al. (1977) noted that in some ways the regression analysis is very misleading. In particular, if, in magnitude estimation, one calculates the correlation between successive responses separately for each pair of stimuli, one finds that the 20 by 20 matrix of correlation coefficients is highly structured. The values along the main diagonal are consistently large and roughly the same. As one runs along lines of cells parallel to the diagonal, the entries continue to be independent of where one is on the line, but with values diminishing with distance from the main diagonal. If we average over each of these parallel lines, i.e., average over signal pairs that differ by a constant decibel value, we obtain the pattern of correlations shown in Figure 4. This replicates closely the result in Jesteadt et al. (1977).

With the production data, the corresponding calculations of correlations of successive settings of intensity as a function of the logarithm of the numerical ratio show the pattern of Figure 5. The similarity between the estimation and production data is striking.

- The interpretation seems to be that subjects manage to respond so as to preserve the stimulus ratio when that ratio is not large, but as it becomes large, the previous response has less and less effect on the correct response. Given the idea of an atten-

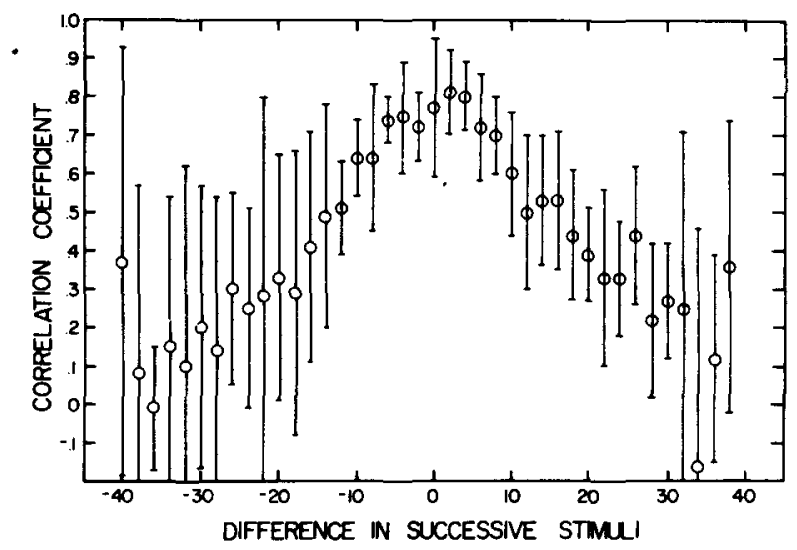

Figure 4. Correlation between successive responses (numbers) in magnitude eslimation averaged over constant differences in the stimuli (dB) vs. these stimulus differences.

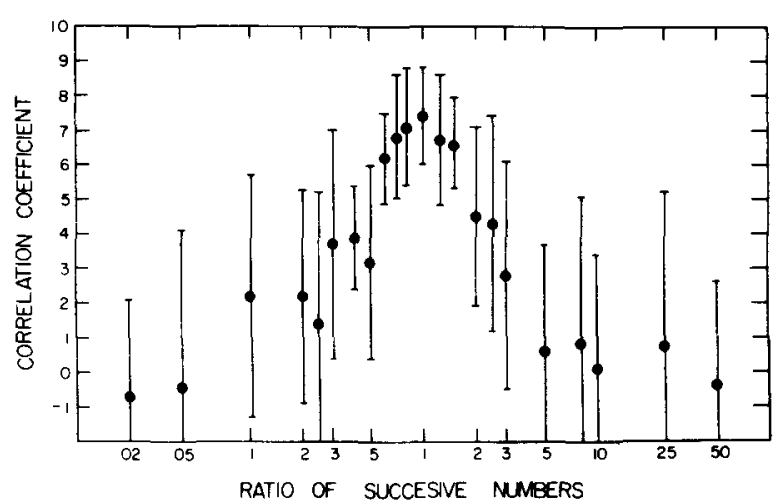

Figure 5. Correlation between successive responses (dB) in magnitude production averaged over constant differences in the stimuli (log numbers) vs. these stimulus differences.

tion band of intensity, which appears to be needed to account for the variability, there is the suggestion that stimulus ratios can be preserved in the responses when and only when the ratio is small enough so that the signals both fall within the band.

Since both the correlation between successive responses and the coefficient of variability change as a function of the decibel difference between successive stimuli, there is the suggestion that the two effects are somehow related. As yet, we have not been able to construct a quantitative model that would support such a conjecture. Indeed, from our viewpoint, the changes in the coefficient of variation arise because of changes in the sample size representing the signal, whereas the changes in the correlation between successive responses depends on different calculations being carried out on the statistics associated with the two successive signals.

\section{SUMMARY}

(1) Variability in response ratio is smaller when the change in stimulus is small and increases for larger changes in stimulus - an effect previously noted and confirmed for production data as well in this experiment.

(2) The variability of the magnitude productions decreases with signal level, except for adjustments near absolute threshold.

(3) Sequential effects as evidenced in a multiple regression are smaller in production than in estimation data, but exhibit a similar influence from previous responses.

(4) The correlation between responses when computed separately for each stimulus pair and averaged over constant stimulus differences (in logarithmic scales) is similar for both production and estimation data, namely, very large for small differences and about zero for larger ones. 
(5) We interpret (1) and (3) as two aspects of a theoretical concept: an attention band of intensity. First, signals falling within the band receive a representation based on a sample about an order of magnitude larger than signals falling outside the band. Second, for two signals falling within the band, their ratio can be estimated and used in emitting the response, whereas for signals too far apart to lie within the band, their ratio apparently cannot be calculated.

\section{REFERENCES}

Batrd, John C. Psychophysical analysis of visual space. New York: Pergamon Press, 1970.

Cross, D. V. Sequential dependencies and regression in psychophysical judgments. Perception \& Psychophysics, 1973, 14, 547-552.

GREEN, D. M., \& LuCE, R. D. Variability of magnitude estimates: A timing theory analysis. Perception \& Psychophysics, 1974, 15, 291-300.

Helson, H. Adaptation-level as a basis for a quantitative theory of frames of reference. Psychological Review, 1948, 55, 297-313.
Holland, M. K., \& Lockhead, G. R. Sequential effects in absolute judgments of loudness. Perception \& Psychophysics, 1968, 3, 409-414.

Jesteadt, W., Luce, R. D., \& Green, D. M. Sequential effects in judgments of loudness. Journal of Experimental Psychology, 1977, 3, 92-104.

Stevens, S. S. Psychophysics. New York: Wiley, 1975.

Stevens, S. S. \& \& Greenbaum, H. B. Regression effect in psychophysical judgment. Perception \& Psychophysics, 1966, 1, 439-446.

WARD, L. M. Category judgments of loudness in the absence of an experimenter-induced identification function: Sequential effects and power-function fit. Journal of Experimental Psychology, $1972,94,179-184$.

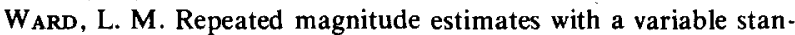
dard: Sequential effects and other properties. Perception \& Psychophysics, 1973, 13, 193-200.

WARD, L. M., \& LockHEAD, G. R. Sequential effects and memory in category judgments. Journal of Experimental Psychology, $1970,84,27-34$.

WARD, L. M., \& LockHEAD, G. R. Response system processes in absolute judgment. Perception \& Psychophysics, 1971, 9, 73-78.

(Received for publication May 24, 1977: revision accepted July 13, 1977.) 